\title{
Iron nanoparticles from blood coated with collagen as a matrix for synthesis of nanohydroxyapatite
}

\author{
M CHAMUNDEESWARI ${ }^{1}$, B SANTHOSH KUMAR ${ }^{2}$, T MUTHUKUMAR ${ }^{2}$, L MUTHURAMAN $^{1}$, \\ K PURNA SAI ${ }^{3}$ and T P SASTRY ${ }^{2 *}$ \\ ${ }^{1}$ St. Joseph's College of Engineering, Sholinganallur, Chennai 600 119, India \\ ${ }^{2}$ Bio-Products Lab, Central Leather Research Institute, Chennai 600 020, India \\ ${ }^{3}$ Biomaterials Division, Central Leather Research Institute, Chennai 600 113, India
}

MS received 27 April 2012; revised 9 September 2012

\begin{abstract}
A simple wet precipitation technique was used to prepare nanobiocomposite containing iron nanoparticles coated with collagen. This nanobiocomposite was used as matrix for the synthesis of nanohydroxyapatite. The physicochemical characteristic studies of the nanohydroxyapatite thus formed were carried out using fourier transform infrared spectroscopy, transmission electron microscopy, scanning electron microscopy, energydispersive $\mathrm{X}$-ray spectroscopy and $\mathrm{X}$-ray diffraction technique to confirm the formation of hydroxyapatite on iron nanoparticle-collagen complex. The results of the above studies supported the formation of iron nanoparticlecollagen-hydroxyapatite composite. The biological studies such as biocompatibility and hemocompatibility were carried out for nanohydroxyapatite using different cell lines and blood sample. The results of biocompatibility and hemolytic assay revealed that the prepared nanobiocomposite was $100 \%$ biocompatible and hemocompatible. This nanobiocomposite may be used for biomedical application such as injectables for targeted delivery and as scaffold for tissue engineering.
\end{abstract}

Keywords. Collagen; iron nanoparticle; nanohydroxyapatite; MTT assay; wet precipitation method.

\section{Introduction}

Bone is a type of connective tissue mainly composed of an organic component, collagen and an inorganic component, nanocrystalline carbonate hydroxyapatite. This type of biological hybrid material finds potential biomedical application in bone tissue engineering by promoting the osteoblast proliferation and differentiation. It is also extensively used in orthopaedic surgery as bone-filling material (Maria and Daniel 2006; Tsai et al 2008). Nanotechnology has gained extensive biomedical applicability in various fields such as nanobiomaterials, nanoparticles (Nps) for the targeted medicine and gene therapy. Among the available inorganic biomaterials, nanohydroxyapatite ( $n \mathrm{HAp})$ is widely used as filler for bone disorders due to its good biocompatibility and osteoconductivity. Apart from its use as bone substitute, it can also be used as a carrier for chemotherapeutic agents such as doxorubicin, mitomycin $\mathrm{C}$ and 5-fluorouracil in cancer treatment (Wang et al 2009). The surface of polymer components containing polyvinyl alcohol-polyvinyl pyrrolidone (PVA-PVP) is chemically multifunctional (surface $\mathrm{OH}$, $\mathrm{COOH}, \mathrm{C}=\mathrm{C}, \mathrm{C}-\mathrm{O}-\mathrm{C}$ and $\mathrm{C}=\mathrm{O}$ groups exist). HAp can be easily grown on such polymer surfaces by two major

\footnotetext{
*Author for correspondence (sastrytp@ hotmail.com)
}

phenomena such as physical adsorption and chemical interaction. Natural biopolymers such as collagen, fibrin, alginate and hyaluronic acid can be used apart from the commercially available synthetic polymers. The precipitation of HAp crystals on polymers can be carried out under mild temperature conditions (Geiger et al 2003; Oudadesse et al 2011). Apart from polymers, the biomedical materials such as metals, ceramics or hybrid combinations can be used for preparing the biomimetic nanocomposites (Tan and Saltzman 2004). The cell viability, attachment and proliferation studies using cell lines were carried out to check the cytocompatibility nature of the nanocomposite scaffolds. Cell lines such as osteosarcoma (MG-63), normal vero cell lines, mouse embryonic fibroblast cells (NIH3T3) and normal human dermal fibroblast ( $n$ HDF) cells are widely used for such purposes. The cell line studies suggest that the prepared material could be a potential candidate for bone and wound tissue engineering purpose (Sudheesh Kumar et al 2011).

Collagen, a biopolymer finds its application in tissue engineering including skin replacement, bone substitutes, artificial blood vessels and valves. Collagen is available in various forms for different applications such as collagen shields in ophthalmology, sponges for burns/wounds, minipellets and tablets for protein delivery, gel formulation in combination with liposome's for sustained drug delivery, as controlling material for transdermal delivery, as ophthalmic inserts, Nps for gene delivery and basic matrices for cell culture systems (Lee et al 2001; Mu et al 2003; Ruszczaka and Friess 2003; 


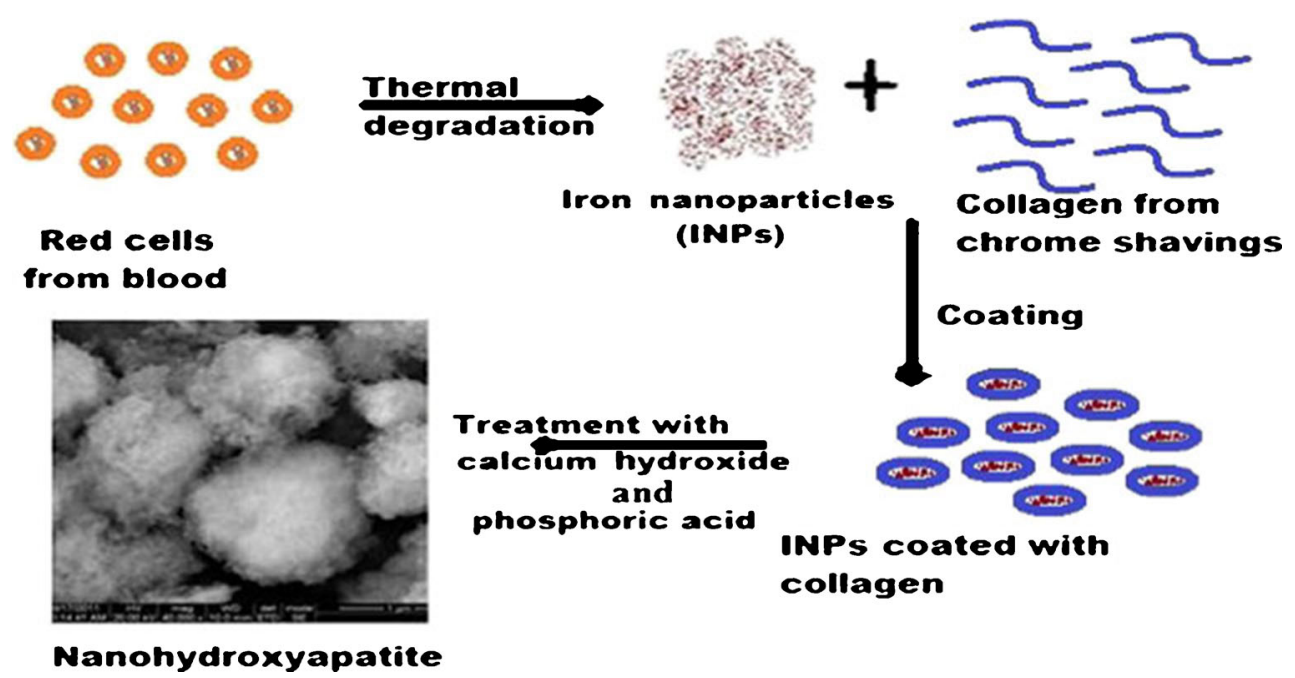

Scheme 1. Graphical representation for preparation and characterization of INP-collagen-HAp.

Huang et al 2009; Nair et al 2010). Chromium-containing leather wastes (CCLW) from post-tanning operations have the potential to generate value-added material like collagen. By alkali and enzymatic hydrolysis of CCLW, various useful products such as gelatin, collagen and chromium-containing retanning agents for leather industry are produced (Mu et al 2003). Hyperthermia, a thermal therapy for cancer has drawn more attention for in vivo cancer treatment. Such treatment is possible with the new magnetic hydroxyapatite nanoparticles which were first made by co-precipitation method (Hou et al 2009).

The biocompatible iron oxide nanoparticles (INPS) find their applications in various fields such as biology, medical diagnostics and therapy. Some of the biomedical applications include targeted drug delivery, diagnostics, biosensors, MRI contrast agents and hyperthermia (Morteza et al 2011). Magnetic scaffolds containing INPS are promising for magnetic guiding in orthopaedic tissue engineering applications and they are suitable to treat several pathologies in regenerative medicine (Panseri et al 2012). Using computer simulations, INPs incorporated hydroxyapatite scaffolds help in investigating the osteogenesis with the guidance of the magnetic field, they generate (Bock et al 2010). So, by considering the wide applicability of INPs, $n$ HAp and collagen as mentioned above, a collagen based metal nanobiocomposite was synthesized in this study, which may act as inorganic biomaterial for bone substitute, as a nanocarrier for chemotherapeutic agent and as hyperthermia agent due to the presence of iron nanoparticles (INPs). The novelty of this study lies in the raw materials used for the preparation of $n$ HAp. The raw materials such as collagen and INPs used for the preparation of nanobiocomposite were isolated from biological waste materials such as CCLW and goat blood from municipal slaughter house. The graphical representation for the preparation and characterization of $n \mathrm{HAp}$ is given below (scheme 1).

\section{Materials and method}

\subsection{Materials}

Goat blood was collected from a nearby municipal slaughter house, CCLW was collected from the Department of Tannery, Central Leather Research Institute, Chennai; MTT (3-(4, 5-dimethyl thiazol-2yl)-2,5-diphenyl tetrazolium bromide) and calcium hydroxide were purchased from Merck Ltd, India and all other chemicals used were of analytical grade. MG-63, NIH3T3, epidermoid carcinoma (A431) and normal Vero cell lines were obtained from the National Centre for Cell Science (NCSS), Pune.

\subsection{Preparation of INPs and collagen from natural waste}

INPs from animal blood was prepared as reported in our earlier studies (Chamundeeswari et al 2011) and briefly elaborated as follows: $1 \mathrm{~L}$ of goat blood was collected and stirred mechanically using a glass rod for 15 min continuously to isolate the fibrin. The defibrinated blood was centrifuged at $7155 \mathrm{~g}$ for $20 \mathrm{~min}$; the supernatant (serum portion) was discarded and the red blood cells (RBC) collected at the bottom of the tube was removed, washed with water for 10 times and stored at $4{ }^{\circ} \mathrm{C}$. RBC was then incinerated in a silica crucible using a muffle furnace at $800^{\circ} \mathrm{C}$ for $2 \mathrm{~h}$. After cooling, the residue (INPs) was collected and stored in a glass container. The collagen was prepared by dechroming CCLW using sulphuric acid. The dechroming was done as follows: CCLW was soaked in water for $24 \mathrm{~h}$. Later the water was decanted and treated with $0.5 \mathrm{~N}$ sulphuric acid for $5 \mathrm{~h}$ and checked for the dechroming (CCLW lot originally exhibits blue colour whereas the dechromed lot shows brown colour). The dechromed sample was then treated with 
$0 \cdot 1 \mathrm{M}$ tris $\mathrm{HCl}(\mathrm{pH} 8), 0.2 \mathrm{M} \beta$-mercaptoethanol, $0.05 \mathrm{M}$ EDTA for 3 days to obtain collagen in fibre form. The collagen fibrils were suspended in $0.05 \mathrm{M}$ acetic acid and digested with $19 \%$ 100:10: dechromed tissue: pepsin at $4{ }^{\circ} \mathrm{C}$ for $24 \mathrm{~h}$. The pepsin solubilized collagen was centrifuged at $7155 \mathrm{~g}$ for an hour. The supernatant was further dissolved in $0.05 \mathrm{M}$ acetic acid and subsequently dialyzed with water and the obtained collagen was stored for further use and analyses.

\subsection{Synthesis of nanohydroxyapatite ( $n H A p)$}

$n$ HAp was prepared by wet precipitation technique. $40 \mathrm{mg}$ of INPs was weighed and dissolved in $600 \mu \mathrm{L}$ of phosphoric acid. To this, $10 \mathrm{~mL}$ of water and $6 \mathrm{~mL}$ of $2 \%$ collagen solution, isolated from CCLW was added and labelled as mixture 1. The mixture 1 was allowed to stand for $15 \mathrm{~min}$. To $1.5 \mathrm{~g}$ of calcium hydroxide, $5 \mathrm{~mL}$ of water and $400 \mu \mathrm{L}$ of $4 \%$ ethanol were added and the solution was labelled as mixture 2. The mixture 2 was then taken in a $100 \mathrm{~mL}$ beaker and kept for stirring at $30^{\circ} \mathrm{C}$. To this, $16 \mathrm{~mL}$ of mixture 1 was added drop wise and after addition, $\mathrm{pH}$ of the resultant solution was found to be 14. $\mathrm{pH}$ was then adjusted to 10 using dilute $\mathrm{HCl}$ followed by stirring for $1 \mathrm{~h}$ and the resulting precipitate was kept for aging at room temperature $\left(30^{\circ} \mathrm{C}\right)$. The precipitate formed was centrifuged, washed repeatedly with water and the final precipitate ( $n \mathrm{HAp}$ ) collected after thorough washing and dried at $100{ }^{\circ} \mathrm{C}$ for $5 \mathrm{~h}$.

\subsection{Characterization}

Fourier transform infrared (FT-IR) spectra of the prepared samples were recorded on a Nicolet 360 FT-IR spectroscope using $\mathrm{KBr}$ pellet containing 2-6 $\mathrm{mg}$ of sample to confirm the presence of HA on collagen. The surface morphology of the composite was visualized by scanning electron microscope (SEM) and elemental analysis was carried out using energy-dispersive X-ray (EDX) spectroscopy. The sample was placed over the aluminum stab containing carbon sheet and air dried for a few minutes. Then the dried specimen was sputter coated with Au and analysed under the following condition: 0.1 Torr pressure, $200 \mathrm{Ma}$ current and 70 s coating time. The surface morphology was visualized by SEM (Hitachi SEM; S-3400N model) using $10 \mathrm{kV}$ as an accelerating voltage. The elemental analysis to estimate the amount of calcium phosphate ratio was carried out using EDX spectroscopy (Thermo EDX) at an accelerating voltage of $10 \mathrm{kV}$. The transmission electron microscopy (TEM) analysis for the prepared sample was carried out using Tecnai 10, Philips TEM to determine the size and shape of the prepared $n$ HAp. The sample was sonicated using Vibronics, Ultrasonicator processor 2 at 180 Watt for 20 cycles, each cycle for $1 \mathrm{~min}$ with a gap of $30 \mathrm{~s}$ after each cycle. These particles were then mixed with $2 \%$ phosphotungstic acid with a ratio of $1: 2$ and $20 \mu \mathrm{L}$ of the mixture was placed in copper grid $260 \#$ and dried at room temperature for analysis. X-ray diffraction
(XRD) analysis of the sample was done using X-ray diffractor GE model 3003TT German, as a further confirmatory study for the formation of $n$ HAp on collagen.

\subsection{Sodium dodecyl sulphate polyacrylamide gel electrophoresis}

Sodium dodecyl sulphate polyacrylamide gel electrophoresis (SDS PAGE) was carried out using Laemmli's method and $8 \%$ gel was prepared. The sample was dissolved in SDS sample buffer solution containing $1 \%$ SDS, $1 \%$ mercaptoethanol and $20 \%$ glycerol and heated for $5 \mathrm{~min}$ at $100{ }^{\circ} \mathrm{C}$. The sample $40 \mu \mathrm{L}(100 \mu \mathrm{g})$ was subjected to gel electrophoresis at a constant current of $5 \mathrm{~V} / \mathrm{cm}$. After electrophoresis, the gel was stained with $0.1 \%$ coomassie brilliant blue R-250 and the gel images were captured on a BIOVIS gel documentation system.

\subsection{Cell culturing studies}

The biocompatibility test for the prepared $n$ HAp was evaluated using MTT assay. The cell lines used to check the biocompatibility are MG-63, A431, normal vero cell line and NIH3T3. They are cultured in $\alpha$-MEM (MG63) and DMEM (NIH3T3, A431 and normal vero cell line) supplemented with $10 \% \mathrm{FBS}, 100 \mathrm{IU} / \mathrm{mL}$ penicillin, $100 \mu \mathrm{g} / \mathrm{mL}$ streptomycin, $30 \mu \mathrm{g} / \mathrm{mL}$ gentamycin, $0.2 \mu \mathrm{g} / \mathrm{mL}$ fungizone and $2.5 \mu \mathrm{g} / \mathrm{mL}$ dimethyl sulfoxide (DMSO). The $n$ HAp was UV sterilized for $2 \mathrm{~h}$ and varying concentrations of the sterilized $n$ HAp 25, 50, 75 and $100 \mu \mathrm{g}$ were added to 48 wells plate at a seeding cell density of $12 \times 10^{3}$ cells/well and incubated for $24 \mathrm{~h}$ at $37^{\circ} \mathrm{C}$ in humidified atmosphere $\left(5 \% \mathrm{CO}_{2}\right.$ in $95 \%$ air). After incubation period MTT was added, incubated for $4 \mathrm{~h}$ and checked for absorbance at $630 \mathrm{~nm}$ using microtitre well plate spectrophotometer (Bio-Rad 680, USA) (Sudheesh Kumar et al 2011).

\subsection{Phase contrast microscopy studies}

$5 \mathrm{~mL}$ of $0.5 \mathrm{mg} / \mathrm{mL}$ INP-collagen-HAp suspension was prepared using sterilized double-distilled water. The sample was sonicated and the suspension was then sterilized by exposing it to UV radiation for $2 \mathrm{~h}$. MG-63 and normal Vero cell lines were used to check the morphological changes of the cells after treatment with $n$ HAp suspension, which may be used as an injectable material. Varying volumes of suspension containing various concentrations of $n \mathrm{HAp}: 5,12.5$ and $25 \mu \mathrm{g}$ for MG-63 and 62.5, 125 and $500 \mu \mathrm{g}$ for normal Vero cell lines were added to visualize the morphological compatibility with the prepared $n \mathrm{HAp}$ suspension.

\subsection{Hemolytic test}

$1 \mathrm{~mL}$ of human blood was collected from a healthy 27 year old volunteer (male). The collected blood was diluted with 


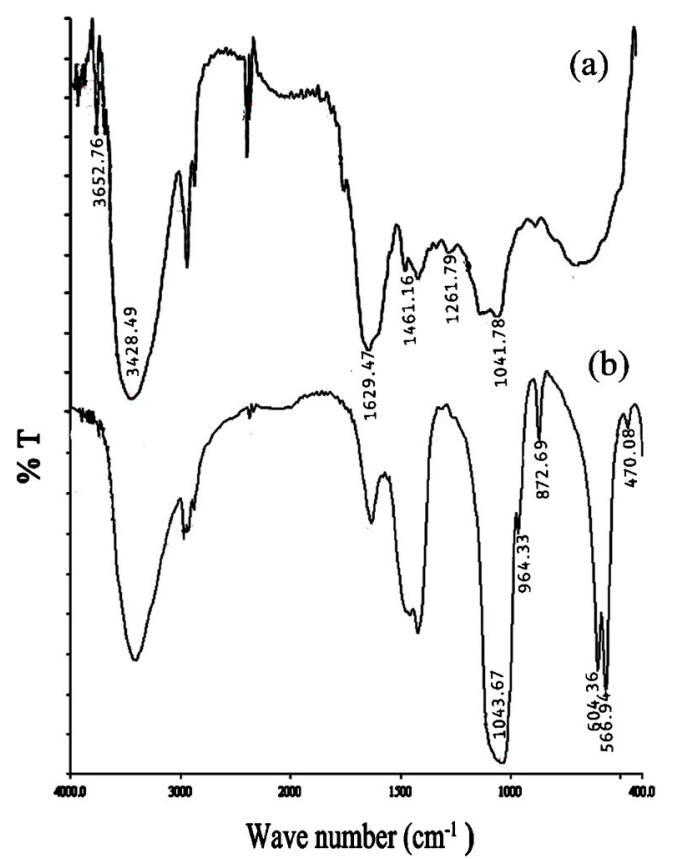

Figure 1. (a) FT-IR spectrum of collagen isolated from CCLW and (b) $n$ HAp formed in INP-collagen complex.

$10 \mathrm{~mL}$ of 4-(2-hydroxyethyl)-1-piperazine ethane sulfonic acid (HEPES) buffer ( $\mathrm{pH} 7.4$ ). Then the diluted blood was centrifuged at $1431 \mathrm{~g}$ for $10 \mathrm{~min}$ at $4{ }^{\circ} \mathrm{C}$. After centrifugation, a buffy coat layer was formed in the supernatant and layer formed was removed using a glass rod. This step was repeated thrice and then the final volume of the solution was adjusted to $10 \mathrm{~mL}$ after complete removal of the buffy coat. Varying volumes of the diluted blood: 5, 10, 20, 30 and $40 \mu \mathrm{L}$ were taken in microfuge tubes, volume of the solution was then adjusted to $1 \mathrm{~mL}$ using distilled water and centrifuged at $1431 \mathrm{~g}$ for $10 \mathrm{~min}$. Then the supernatant was measured at $540 \mathrm{~nm}$ using spectrophotometer. The microfuge tube containing $40 \mu \mathrm{l}$ of diluted blood showing an OD value of 0.24 was selected, which shows a high hemoglobulin content. This particular volume was selected to check the hemocompatibility of the prepared $n$ HAp. $40 \mu \mathrm{L}$ of diluted blood was added to the microfuge tubes, containing varying concentrations of $n \mathrm{HAp}: 25,50,75$ and $100 \mu \mathrm{g}$ of $n \mathrm{HAp}$ and the volume was adjusted to $1 \mathrm{ml}$ using HEPES buffer. Two microfuge tubes, one without $n \mathrm{HAp}$ (positive control) and another with HEPES buffer alone (negative control) were used as controls for this experiment. The above tubes were incubated at $37{ }^{\circ} \mathrm{C}$ for $30 \mathrm{~min}$ and centrifuged at $1431 \mathrm{~g}$ for $10 \mathrm{~min}$. Then, the microfuge tubes were viewed for free hemoglobin in the supernatant (Li et al 2009).

\section{Results and discussion}

FT-IR spectra (figure $1(\mathrm{a}, \mathrm{b})$ ) of $n$ HAp prepared using collagen as matrix shows characteristic absorption bands of both collagen and HAp. The characteristic amides I, II and
III absorption bands of collagen (Figure 1(a)) were found at 1629,1585 and $1241 \mathrm{~cm}^{-1}$, respectively. The hydroxyl groups present in the collagen molecules are seen as a broad peak from $3500-3100 \mathrm{~cm}^{-1}$ (Palpandi et al 2010). The vibration modes of $v 1, v 3$ and $v 4$ of the phosphate ions in $n \mathrm{HAp}$ (figure 1(b)) were also observed. $v 3$ band was observed around $1043 \mathrm{~cm}^{-1}$ and $\nu 4$ vibration modes were observed at 604,566 and $470 \mathrm{~cm}^{-1}$. The peak at $872 \mathrm{~cm}^{-1}$ shows presence of $\mathrm{HPO}_{4}^{-3}$ ions and a band at $964 \mathrm{~cm}^{-1}$ represents $v 1$ stretching modes of the phosphate. These bands and their positions in FT-IR spectrum indicate the formation of $n \mathrm{HAp}$ on INP-collagen complex (Sastry et al 2008; Chamundeeswari et al 2010). XRD diffraction peaks at 31.7, 45.3 and $56.2^{\circ}$ indicate reflections from 112, 222 and 004 crystal planes, respectively (see ESI). These reflections more or less correspond to the Bragg reflections of $n \mathrm{HAp}$ (Tsai et al 2008; Ko et al 2011). These results show that $n \mathrm{HAp}$ was formed on INP-collagen complex. SEM images (see ESI) of the individual and aggregate particles of the samples show that they are spherical in shape with a particle size in the range of 6-19 $\mathrm{nm}$. However, the aggregated particle size was found to be $19 \mathrm{~nm}$ and they resemble flower-like porous crystalline structure. EDX spectrum (see ESI) has shown presence of calcium and phosphorus in the composite with a ratio of $1 \cdot 64: 1$, which is nearer to that of $n$ HAp (Sundaraseelan and Sastry 2007). The presence of Fe indicates that the composite formed was metal nanobiocomposite (INP-collagen-HAp). TEM studies (see ESI) revealed shape and size of the nanobiocomposite particles. The particle shape varies from spherical to ovoid with size in the range of 6-19 $\mathrm{nm}$. Due to the aggregation of Nps, some of the particles are seen to be large and TEM micrograph clearly exhibits crystalline nature of the sample (Sanosh et al 2009). SDS PAGE results (see ESI) revealed that the isolated biopolymer from CCLW was type I collagen by displaying one $\beta$ band and two $\alpha$ bands $\left(\alpha_{1}\right.$ and $\alpha_{2}$ ) which were unfolding polypeptide chains of the triple helix. These patterns were similar to the collagen isolated from the cat fish (Tachysurus maculatus) by pepsin digestion (Bama et al 2010). MTT assay is an in vitro analysis, which is used to check biocompatibility of the prepared biomaterial. This assay is a pre-requisite to carry out in vivo analysis and also elaborates the biological/cellular responses such as cell viability, attachment and proliferation, alkaline phosphatase activity and osteocalcin formation. In the present work, in vitro study is carried out using both osteoblast and fibroblast cell lines such as MG 63, NIH3T3, $n$ HDF (human dermal fibroblast) and murine fibroblast L929. This study exhibits a high biocompatibility and adhesion property, which has been reported in earlier works (Zhang et al 2003; Nabakumar et al 2009; Sudheesh Kumar et al 2011). MG 63 which is widely used cell line for MTT assay of HAp is employed in this study (Zhang and Zhang 2004; Sohn et al 2006; Teixeira et al 2007). MTT assay carried out for $n \mathrm{HAp} /$ collagen/alginate composite (Zhang et al 2003), $n$ HAp scaffolds (Teixeira et al 2007), HAp/chitosan phosphate nanobiocomposite (Nabakumar et al 2009), anodized titanium coated with 
a

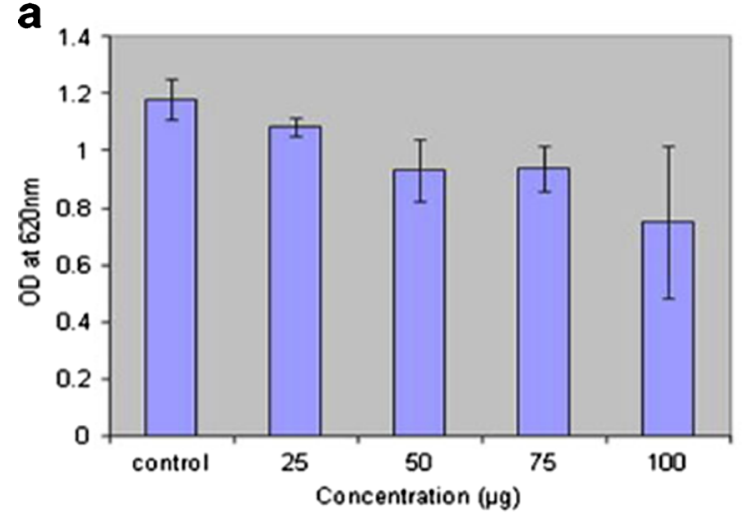

b

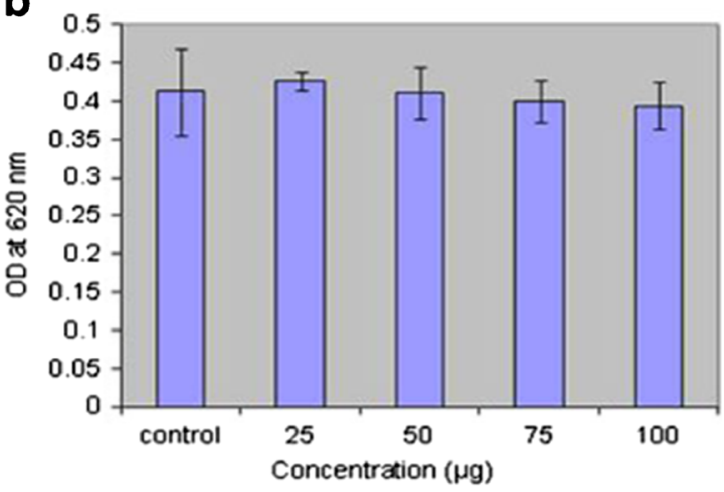

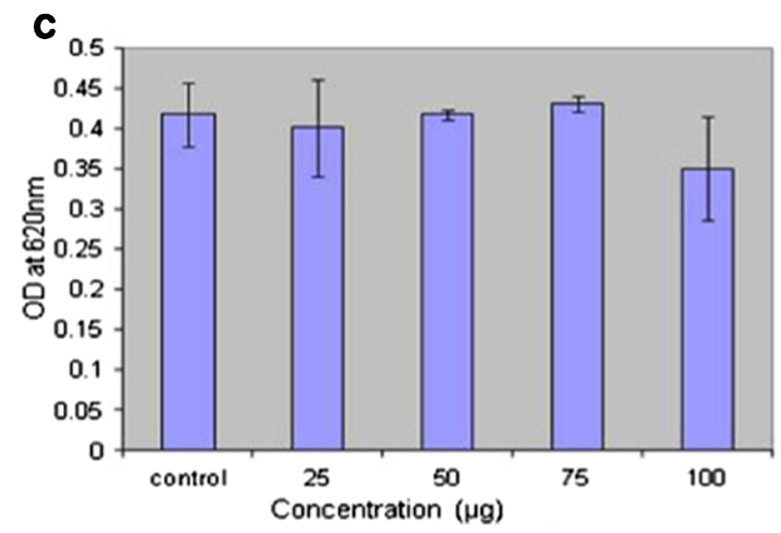

Figure 2. MTT assays of normal and cancer cell lines (a) mouse embryonic fibroblast cells (NIH3T3), (b) osteosarcoma (MG-63) cells and (c) epidermoid carcinoma (A431) cells treated with varying concentrations of $n \mathrm{HAp}$ : $25-100 \mu \mathrm{g} /$ well containing $12 \times 10^{3}$ cells.

HA (Sohn et al 2006), $\alpha$-chitin hydrogel $/ n$ HAp composite scaffold (Sudheesh Kumar et al 2011) and biomimetic $n$ HAp/polymer matrix such as PVP and PVA (Oudadesse et al 2011) exhibited high biocompatibility. Similarly in our study, MTT assay was carried out using cell lines such as NIH3T3 (figure 2(a)), MG 63 (figure 2(b)) and A431 (figure 2(c)) with varying concentrations of $n$ HAp composite. $25-75 \mu \mathrm{g}$ of $n \mathrm{HAp}$ shows high viability rates that are comparable with the control. In the case of MG 63 cell lines treated with $100 \mu \mathrm{g}$ of $n \mathrm{HAp}$ shows slight decrease in viability rate when compared to control and this may be due to overloading of $n \mathrm{HAp}$ to cell lines. The high viability exhibited by $n$ HAp treated normal and A431 cells support that the prepared $n \mathrm{HAp}$ is biocompatible and can be used for various biomedical applications. The magnetic nanoparticles (MNPs) in the form of maghemite can be used for biological applications such as MRI contrast agent, cell labelling and tracking. This type of MNPs exhibited good biocompatibility (Yajie et al 2011; Mornet et al 2002) and comparatively similar result has been obtained in our study for INPs (maghemite) coated with collagen being used as a matrix for the growth of $n \mathrm{HAp}$. Thus prepared novel $n \mathrm{HAp}$ may also be tried as a scaffold in tissue engineering as an osteoinductive material and as nanocarrier for chemotherapeutic agents (Mateus et al 2007; Wang et al 2009).

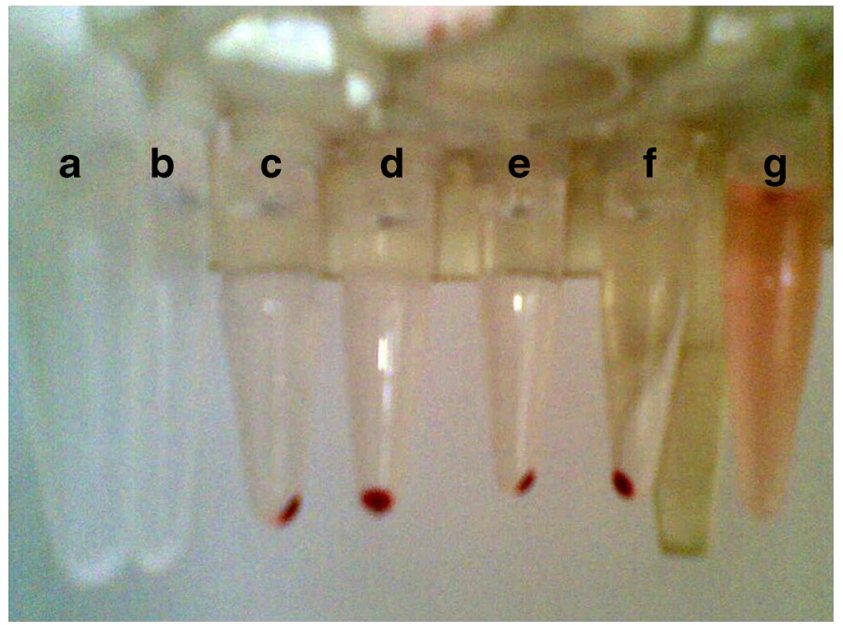

Figure 3. Visual observation of hemolytic tests $(\mathbf{a}, \mathbf{b})$ positive controls treated with buffer solution alone, (c-f) varying concentration of $n$ HAp (25-100 $\mu \mathrm{g})$ treated red cells showing absence of hemolysis and (g) negative control containing water and red cells which shows the presence of hemolysis.

Phase contrast microscopy observations (see ESI) of $n$ HAp treated MG-63 and normal Vero cell lines revealed a high density live adherent cells similar to that of control 
cells (untreated) even after $24 \mathrm{~h}$ incubation (Hua et al 2008; Peng et al 2011). The visual observation of hemolytic test (figure 3) shows absence of red cell lysis in positive control and $n$ HAp $(25-100 \mu \mathrm{g})$ treated samples, but hemolysis was observed in negative control. The absence of hemolysis in treated cells proves good hemocompatibility and suggests that the prepared nanobiocomposite may be used as an effective biomedical material that might have clinical applications, in particular, as substrates for tissue engineering purposes and as nanocarrier for chemotherapeutic agents.

\section{Conclusions}

$n$ HAp was prepared using INP-collagen as a matrix. The physiochemical studies have proved the synthesis of $n \mathrm{HAp}$ and the cell culture studies revealed that the nanobiocomposite might be tried as a carrier for chemotherapeutic agents in targeted delivery system.

\section{Acknowledgments}

The authors would like to thank Mr Sekar, Research Associate, CLRI, Chennai, for helping in the preparation of collagen from CCLW, Mr Venkat and Ms Rachita, Biomaterials Division CLRI, Chennai, for helping in cell line studies, Mr Sridharan and Hemachandran for preparing graphical abstract and Khemlal Adikarai, Technical Assistant, St Joseph's College of Engineering, Chennai, for helping in the collection of goat blood.

\section{Electronic Supplementary Material}

Electronic supplementary material pertaining to this article is available on the Bulletin of Materials Science website (www. ias.ac.in/matersci).

\section{References}

Bama P, Vijayalakshmi M, Jayasimman R, Kalaichelvan P T, Deccaraman M and Sankaranarayanan S 2010 Int. J. Pharm. Pharm. Sci. 2133

Bock N et al 2010 Acta Biomater. 6786

Chamundeeswari M, Liji S S, Justin P J, Ganesh K M, Pandima D M, Sastry T P and Mandal A B 2010 Biotechnol. Appl. Biochem. 5529
Chamundeeswari M, Senthil V, Kanagavel M, Chandramohan S M and Sastry T P 2011 Mat. Res. Bull. 46901

Geiger M, Li R H and Friess W 2003 Adv. Drug Deliv. Rev. 551613

Hou C H, Hou S M, Hsueh Y S, Lin L, Wu H C and Lin F H 2009 Biomaterials 303956

Hua W H, Bo L, Da L G, Zhi X H and Zhi Q C 2008 Key Eng. Mater. 3681261

Huang Z, Tian J, Yu B, Xu Y and Feng Q 2009 Biomed. Mater. 41

Ko Y H, Seo D S and Lee J K 2011 Biocera. Develop. Appl. 11

Lee C H, Singla A and Lee Y 2001 Int. J. Pharm. 2211

Li X Y, Liu G Q, Yuan S D, Zhang L and Meng X C 2009 Mater. Sci. Forum 6101215

Maria V M and Daniel A 2006 Curr. Nanosci. 2179

Mateus A Y P, Barrias C C, Ribeiro C, Ferraz M P and Monteiro F J 2007 J. Biomed. Mater. Res. A 86483

Mornet S, Grasset, Portier J and Duguet 2002 Eur. Cells Mat. 3 2002

Morteza M, Shilpa S, Ben W, Sophie L and Tapas S $2011 A d v$. Drug Deliv. Rev. 6324

Mu C, Lin W, Zhang M and Zhu Q 2003 Waste Manage. 23835

Nabakumar P, Debasish M, Indranil B, Tapas K, Parag B and Panchanan P 2009 Int. J. Biomat. 20091

Nair R, Sevukarajan M, Badivaddin T M and Ashok Kumar C K 2010 J. Innov. Trends Pharm. Sci. 1288

Oudadesse H, Mostafa A, Bui X V, Foad E, Kamal G, Legal Y and Cathelineau G 2011 Int. J. Biomed. Eng. Tech. 5103

Palpandi C, Ramasamy P, Rajinikanth T, Vairamani S and Shanmugam A 2010 Am-Euras. J. Sci. Res. 523

Panseri S et al 2012 J. Biomed. Mater. Res. 100A 2278

Peng L, Dong W, Hai Y S, Liang L, Shu W L and Jin D H $2011 J$. Clin. Rehab. Tissue Eng. Res. 157831

Ruszczaka Z and Friess W 2003 Adv. Drug Deliv. Rev. 551679

Sanosh K P, Chu M C, Balakrishnan A, Kim T N and Cho S J 2009 Bull. Mater. Sci. 32465

Sastry T P, Sundaraseelan J, Swarnalatha K, Liji S S, Uma M M, Sekar S and Mandal A B 2008 Nanotechnology 191

Sohn S H, Jun H K, Kim C S, Kim K N, Chung S M, Shin S W, Ryu J J and Kim M K 2006 J. Oral Reh. 33 898

Sudheesh Kumar P T, Srinivasan S, Lakshmanan V K, Tamura H, Nair S V and Jayakumar R 2011 Carbohydr. Polym. 85 584

Sundaraseelan J and Sastry T P 2007 J. Biomed. Nanotechnol. 31

Tan J and Saltzman W M 2004 Biomaterials 253593

Teixeira S et al 2007 Eur. Cells Mat. 1495

Tsai S W, Hsu F Y and Chen P L 2008 Acta Biomater. 41332

Wang R M, He N P, Song P F, Feng H Y, Ding L and Lei Z Q 2009 Polym. Advan. Technol. 20959

Yajie W, Yanming W, Ling W, Yongzhe C, Zongjin L and Deling K 2011 J. Nanosci. Nanotechnol. 113749

Zhang Y and Zhang M 2004 J. Mat. Sci: Mater. Med. 15255

Zhang S M, Cui F Z, Liao S S, Zhu Y and Han L 2003 J. Mater. Sci: Mater. Med. 14641 